\title{
Functional and aggregative response of North Sea whiting
}

\author{
Rindorf, Anna; Gislason, Henrik
}

Published in:

Journal of Experimental Marine Biology and Ecology

Link to article, DOI:

10.1016/j.jembe.2005.04.013

Publication date:

2005

Document Version

Peer reviewed version

Link back to DTU Orbit

Citation (APA):

Rindorf, A., \& Gislason, H. (2005). Functional and aggregative response of North Sea whiting. Journal of Experimental Marine Biology and Ecology, 324(1), 1-19. https://doi.org/10.1016/j.jembe.2005.04.013

\section{General rights}

Copyright and moral rights for the publications made accessible in the public portal are retained by the authors and/or other copyright owners and it is a condition of accessing publications that users recognise and abide by the legal requirements associated with these rights.

- Users may download and print one copy of any publication from the public portal for the purpose of private study or research.

- You may not further distribute the material or use it for any profit-making activity or commercial gain

- You may freely distribute the URL identifying the publication in the public portal

If you believe that this document breaches copyright please contact us providing details, and we will remove access to the work immediately and investigate your claim. 


\title{
Functional and aggregative response of
}

\section{North Sea whiting}

\author{
A. Rindorf ${ }^{\dagger}$ and H. Gislason
}

Danish Institute for Fisheries Research, Charlottenlund Castle, DK2920

10 Charlottenlund, Denmark.

†Corresponding author. Tel: +45 339633 59. Fax: +45 339633 33. Email:

ar@dfu.min.dk

\section{Abstract}

The functional response of whiting (Merlangius merlangus L.) to clupeid and gadoid prey was determined from estimates of food intake and prey density at five locations in the North Sea. The intake of most prey types was well described by a type II (decelerating) response, although in some cases a type III (sigmoid) response 20 provided a slightly better fit. Though a saturation level was reached for all types of fish prey, none of the levels corresponded to the maximum digestive capacity of the predator. This was not caused by ingestion of other prey as the amount of other food and fish prey ingested were not negatively correlated. An investigation of the occurrence of fresh fish in the stomachs revealed that fish was ingested almost 
25 exclusively during dawn and dusk and the lack of negative correlation between the intake of fish and other prey may thus be a result of the limited time in which fish prey was vulnerable to predation. No aggregative response of the predators was detected towards any of the prey and catches of prey and predators were slightly negatively correlated. There was evidence of an increase in mortality with density at

30 low clupeid densities, but mortality decreased to virtually zero at high densities. Whiting seem therefore unlikely to impose a regulatory effect on their fish prey outside a narrow range of prey densities.

\section{Keywords}

Aggregative response, food intake, functional response, predator specialisation, whiting

\section{Introduction}

The relationship between the food intake of predators and the density of their

40 prey is one of the classical topics in ecology. Holling (1959) classified the relationship into three different types of functional responses. Common to these responses is zero consumption at low prey density and saturation at high density. Saturation is either reached when food intake equals the maximum digestive capacity of the predator or when the predator spends all its time capturing and handling the prey (Holling, 1959;

45 Jeschke et al., 2002). The three functional responses differ only in the rate at which the saturation level is approached: the increase in consumption is linear in the type I response, decelerating in type II and sigmoid in type III. In the absence of additional responses to prey density such as changes in predator growth and aggregation only predators conforming to a type III response have the ability to stabilise the population 
50 size of their prey (Murdoch and Oaten, 1975). The shape of the functional response can therefore have profound effects on the stability of interacting prey and predator populations.

Several examples of aquatic predators conforming to one of the basic functional response types have been reported from laboratory experiments (Krylov,

55 1992; Buckel and Stoner, 2000; Wennhage, 2002). However, investigations of the response of marine fish in their natural habitats remain scarce (i.e. Abrams and Ginzburg, 2000). Laboratory experiments where the predator is offered one particular prey type in an artificial environment can unfortunately not readily be generalised to a heterogeneous natural environment (Colton, 1987; Krylov, 1992; Abrams and

60 Ginzburg, 2000; Buckel and Stoner, 2000; Wennhage, 2002). There are furthermore numerous examples of changes from one type of functional response to another as experimental conditions change (Townsend and Risebrow, 1982; Lipcius and Hines, 1986; Anderson, 2001; Koski and Johnson, 2002). Even when the type of functional response remains the same, the initial rate of increase in intake at low prey densities,

65 saturation level or both may change. High patchiness of prey decreases the initial rate of increase, but should in theory not affect the saturation level (Essington et al., 2000). Decreased prey detectability may affect both the initial rate of increase and the saturation level (Townsend and Risebrow, 1982; Lipcius and Hines, 1986). The presence of prey refuges has been shown to decrease the saturation level of bluefish

70 (Pomatomus saltatrix L.) (Buckel and Stoner, 2000), and may partly explain the lack of correspondence between digestive capacity and saturation level of fish predators in their natural environment (Essington et al., 2000). It is also possible that diel changes in prey availability impose an upper limit to the food intake by restricting the time available to capture the prey. Diel cycles in the intake of different prey types by 
75 whiting (Merlangius merlangus L.) have been observed for benthic prey (Rindorf, 2003), whereas dawn and dusk have been reported as important feeding periods for other piscivorous predators (Hobson, 1968; Gordon, 1977; Major, 1977; Hobson, 1986). Alternatively, if individual predators specialize on different prey types, the predator population will appear to be saturated when the prey specialists are saturated rather than when all predator individuals are saturated (Chesson, 1984).

The functional response of the individual predator is not the sole determinant of the mortality a predator can impose on its prey. If predators tend to aggregate in areas with high prey densities (an aggregative response), prey mortality may increase with density even when the mortality induced by the individual predator has reached a 85 plateau in these areas (Holling, 1959; Murdoch and Oaten, 1975). As prey are likely to attempt to avoid areas of high predator concentrations, the effect of the aggregative response will be a balance resulting from the actions of the predator and the prey (Anderson, 2001). It is the combination of the functional response of the predator and the changes in spatial overlap of the predator and prey that determines whether the mortality imposed by the predator increases with overall prey density (positive density dependence), decreases with overall prey density (inverse density dependence) or is independent of overall prey density (density independence). Several authors have concluded that positive density dependence is necessary to stabilize interacting predator and prey populations (Murdoch, 1994; Pelletier, 2000).

95 This study presents an investigation of the functional and aggregative response of North Sea whiting (Merlangius merlangus) feeding on sprat (prattus sprattus L.), herring (Clupea harengus L.) and juvenile gadoids (gadidae) in a natural environment. Whiting is a major fish predator in the North Sea ecosystem and annually consumes an amount of herring equal to as much as $30 \%$ of the standing stock (ICES, 1997). 
100 The data used here consisted of whiting stomach contents and relative fish densities obtained by trawling at five locations in the North Sea. The first objective of the study was to investigate whether the intake of sprat, herring and juvenile gadoids by whiting reached a saturation level at high prey densities and whether this level was determined by the digestive capacity of the predator. The extent to which diel changes in fish

105 consumption were present and the possibility that only part of the whiting population was engaged in fish feeding were also investigated. A second objective was to determine the short term population effects of adult whiting on the three prey species. This was done by estimating a mortality index for each prey and relating this index to prey density.

\section{Methods}

\section{Data}

Fish were caught by bottom trawl at five locations in the North Sea in early September (Fig. 1). The locations were chosen from prior knowledge of fish

115 distributions to assure that a reasonable amount of whiting was caught and to represent areas of different prey densities. Both depth and temperature differed between locations (Table 1). The sampling procedure has been described in detail elsewhere as has the estimation of the occurrence and weight of different prey items in the whiting stomachs collected (Rindorf, 2002; 2003; 2004). Briefly, trawl hauls

120 were performed at four hour intervals for a total of 48 to 72 hours. The catch of fish was sorted to species, counted and measured to the nearest $\mathrm{cm}$ below. Large whiting were divided into $5 \mathrm{~cm}$ length categories: 20 to $24.9 \mathrm{~cm}, 25$ to $29.9 \mathrm{~cm}$ and 30 to 34.9 $\mathrm{cm}$. Their stomach contents were examined individually and prey were determined to species, counted and weighed individually. Prey found in the buccal cavity was 
125 discarded from the data as such prey was assumed to have been eaten in the trawl. Prey found in the stomachs was assigned one of the digestion categories 'very fresh' (prey in pristine condition) 'fresh' (whole prey) and 'old' (prey in more advanced stages of digestion). Prey recorded as 'very fresh' was excluded from the estimation of consumption as they may have been eaten in the trawl.

130

\section{Food intake}

The analyses of functional response focussed on sprat, herring and juvenile whiting as these occurred in the diet of whiting at 4 or 5 of the locations and were caught by the trawl at all locations. In addition, the prey species haddock

135 (Melanogrammus aeglefinus L.) and Norway pout (Trisopterus esmarki L.) were examined. These two species were eaten at one location only, and their functional response could therefore not be determined. However, they were included in analyses of the functional response to total gadoid (whiting, haddock and Norway pout) prey density.

The average daily food intake of whiting was estimated by combining estimates of average stomach content with literature estimates of stomach evacuation rates. The estimation was based on the stomach evacuation model of Andersen $(1998,2001)$ in which evacuation is a function of the square root of the weight of the stomach content, energy density of the prey, temperature and predator size. The average hourly intake

145 of species $i, W_{i}$, by each predator size group at each location was calculated over a 48 hour period as

$$
W_{i}=\frac{\rho_{i}^{\prime}}{13} \sum_{j=1}^{13} \sqrt{S_{i, j}}+\frac{1}{48}\left(\hat{S_{i, 13}}-\hat{S_{i, 1}}\right)
$$


where $\hat{S_{i, j}}$ is the average content of species $i$ in the stomachs in sample $j, \sqrt{S_{i, j}}$ is the average square root of the contents, 13 is the number of samples taken in 48 hours 150 (including both endpoints) and 48 is the number of hours in the sampling interval (Rindorf and Lewy, in press.). The data was limited to 48 hours at all locations to make the estimates of food intake at different locations directly comparable. The details of the calculations are given in the appendix.

The intake of each prey was calculated relative to the maximum food intake of 155 the predator (Arrhenius and Hansson, 1994; Essington et al., 2000). This procedure has several advantages. First of all, digestive capacity is affected by temperature and predator size and the maximum intake in $\mathrm{g} /$ day therefore varies between locations and size groups. By measuring the number of prey ingested per day relative to the maximum number which can be ingested, $P_{i}$, the saturation level can be compared directly with digestive capacity and is furthermore comparable both between locations and size groups. $P_{i}$ can be expressed as:

$P_{i}=\frac{n_{i}}{n_{\max , i}}=\frac{W_{i} / w_{i}}{W_{\max } / w_{i}}=\frac{W_{i}}{W_{\max }}$

where $n_{i}$ is the number of prey ingested per day, $n_{\max , i}$ is the maximum number of prey

$165 i$ that can be ingested daily, $W_{\max }$ is the maximum weight that can be ingested daily and $w_{i}$ is the average weight of prey at ingestion. The estimation of the maximum daily food intake is described in the appendix. As maximum food intake depends on temperature and predator size (appendix), one estimate of $W_{\max }$ was estimated for each predator size group at each location.

Apart from the fish species considered here, the diet consisted of crustaceans, krill, benthic invertebrates and juvenile flatfish (Rindorf, 2003). Due to lack of information on their abundance, the functional response to these prey groups could 
not be determined. However, the total consumption of other prey was calculated and compared to the total intake of fish other than flatfish to determine if the presence of 175 other food was likely to constrain the intake of fish prey.

\section{Density of fish prey}

The density of fish prey was estimated from trawl catches. The trawl catch of species $i, T_{i}$, was assumed to be proportional to the local density, $N_{i}$ (Hilborn and

180 Walters, 1992):

$T_{i}=q_{i} N_{i}$

where $q_{i}$ is a species specific catchability coefficient. The average trawl catch of all possible prey of the five species was calculated by first estimating the total catch of each prey for each time of day. The proportion of the total catch of each species that

185 consisted of possible prey, $\gamma$, was then calculated by estimating the proportion of the catch that was of a length less than or equal to the maximum prey size observed in the whiting stomachs, $\mathrm{L}_{\mathrm{c}}$. The average catch at each location was calculated as the average of the catch of possible prey over the course of the diel cycle:

$\hat{T}=\frac{\hat{p}}{6} \sum_{k=1}^{k=6} \hat{\gamma}_{k} \hat{\tau}_{k}$

190 where $k$ denotes time of day (4-hour sampling intervals), $\hat{p}$ is the proportion of all hauls taken at the location which contained the species and $\hat{\tau}_{k}$ the geometric average number of fish of this species caught at time $k$ in trawl hauls where the species occurred (Pennington, 1983). The calculation of the variance of the estimated trawl catch is described in the appendix.

195

\section{Functional response}


Type II and type III functional responses were fitted to the amount of prey ingested relative to the maximum by estimating the parameters in the general functional response model for each combination of prey species and predator length 200 group (Real, 1979; Wennhage, 2002):

$P=\frac{K N^{\beta}}{\chi^{\beta}+N^{\beta}}$

$\beta$ is an exponent that describes the form of the functional response curve ( $\beta=1$ : type II, $\beta>1$ : type III), $K$ corresponds to the saturation level relative to maximum digestive capacity $(0 \leq K \leq 1)$ and $\chi$ is the density of fish which allows the predator to reach half

205 the saturation level. $K$ can be transformed to the absolute saturation level by multiplication with the maximum number of prey eaten per day. Inserting (2) in (4), the relationship between the amount of food ingested and the trawl catch becomes:

$$
P=\frac{K T^{\beta}}{(q \chi)^{\beta}+T^{\beta}}
$$

Note that $K$ can be estimated directly whereas $\chi$ can only be estimated as the trawl

210 catch corresponding to half saturation, $q \chi$. The parameters in (5) were estimated by minimising the squared difference between the natural log to the observed food intake and the natural $\log$ to the intake predicted by equation (5). Logged values were used as the variance of both the trawl catch and the estimated consumption increased as a function of the mean. The locations at which no prey of the particular species had 215 been eaten were excluded from the estimation, as the variance of zero consumption could not be estimated. The Marquardt algorithm for non-linear minimization in SAS $^{\circledR}$ version 8 for Windows ${ }^{\circledR}$ was used to estimate the parameters.

The type II response was fitted by fixing the parameter $\beta$ to 1 . As the number of parameters is high relative to the number of different prey densities, the residual 
220 degrees of freedom never exceeded 2 and this is likely to render the results of any test of the fit of a type II relative to a type III questionable. Further, as neither the variance of the trawl catch nor the variance of the consumption were negligible, traditional regression techniques can not be applied (Kendall and Stuart, 1961). Instead of performing tests, both the type II and type III relationship was therefore fitted and 225 plotted in cases where the prey was eaten at all five locations.

It is often difficult to discriminate visually between a type II response and a type III response (Fig. 2A). However, if both axis are logarithmic, the difference between the two becomes much clearer, in particular in the case where several observations below $\chi$ are made (Fig. 2B). Taking the log on both sides of (5) gives $\ln P=\ln \frac{K}{(q \chi)^{\beta}+T^{\beta}}+\beta \ln T$

and hence $\ln P$ is approximately a linear function of $\ln T$ with slope $\beta$ for $T<<q \chi$ (Fig. 2). This transformation makes even moderate values of $\beta$ easily discernable. In the cases where the prey was eaten at less than 5 locations, only the type II relationship was fitted to avoid estimates based on only one residual degree of 235 freedom.

Apart from the species-specific functional response, the response to the prey groups clupeids (herring and sprat) and gadoids (whiting, haddock and Norway pout) was estimated. The first group represented schooling prey whereas the latter group consisted of non-schooling, more demersal prey (Bailey, 1975; Bromley and Kell, 240 1995). The grouping of species is only valid if the parameters in the functional response model of all prey species in the group are similar. As the catchability of demersal juvenile gadoids is likely to be higher than that of pelagic clupeids, it was not attempted to fit one common functional response to all fish prey. 
Single species and prey group functional responses may not be accurate in the 245 presence of varying amounts of other prey (Krylov, 1992; Mattila and Bonsdorff, 1998). Murdoch (1973) therefore suggested using a multispecies type II functional response, where the intake rate of prey $i, n_{i}$, is given by

$$
n_{i}=\frac{a_{i}^{\prime} N_{i}}{1+\sum_{m=1}^{m=M} a_{m}^{\prime} t_{m}^{\prime} N_{m}}
$$

where $a_{i}^{\prime}$ and $t_{i}^{\prime}$ is the attack rate and handling time, respectively, for prey $i, m$ denotes

250 prey type and $M$ is the number of types. Dividing by the maximum intake and inserting (2), the model becomes

$$
P_{i}=\frac{a_{i} T_{i}}{1+\sum_{m=1}^{m=M} a_{m} t_{m} T_{m}}
$$

where $a_{i}=a_{i}^{\prime} q_{i}^{-1} n_{\max , i}^{-1}$ and $t_{i}=t_{i}^{\prime} n_{\max , i}$. The parameters are directly related to the parameters in the single species type II responses as formulated in (5) as $K_{i}=t_{i}^{-1}$ and $255 q_{i} \chi_{i}=a_{i}^{-1} t_{i}^{-1}$. The parameters in this multispecies functional response model were estimated by minimising the sum of squared deviations between the natural log to observed and predicted intake relative to the maximum. The Marquardt algorithm for non-linear minimization in $\mathrm{SAS}^{\circledR}$ version 8 for Windows ${ }^{\circledR}$ was used. One observation corresponded to the intake of one prey species at one location. As the species haddock and Norway pout were only consumed at one location, they were joined with whiting in a gadoid prey group. The model was fitted for the two larger predator groups only as fish consumption of the smallest predator group was low at several locations.

\section{Diel cycles in fish consumption}


In the analyses of functional response, prey classified as 'very fresh' were assumed to have been eaten in the trawl (Main and Sangster, 1981) and discarded. This led to the conclusion that newly ingested prey was virtually absent from the stomachs at the location where fish consumption was highest. This seemed unrealistic. Including 'very fresh' prey when analysing diel cycles in food intake may positively 270 bias the pattern, but the bias should enhance the diel pattern rather than alter it, if feeding in the trawl is governed by the same mechanism as feeding in the wild (e.g. light levels). In contrast, discarding 'very fresh' prey will lead to underestimation of the amount of newly ingested food in the periods of intense feeding on this prey and thereby dampen the diel changes. Based on these considerations, it was decided to combine 'very fresh' and 'fresh' prey and include all prey found in the stomachs in the investigation of diel feeding cycles and predator specialisation.

To determine if a diel cycle in the intake of fish prey could be detected, the occurrence of 'very fresh' and 'fresh' fish in the stomachs was examined. Diel changes were investigated by calculating the proportion of prey at each location and time of day which was classified as 'very fresh' or 'fresh', $n_{\text {fresh }, i} /\left(n_{\text {fresh }, i}+n_{\text {old }, i}\right)$, where $n_{\text {fresh,i }}$ is the number of prey of species $i$ recorded as 'very fresh' or 'fresh' and nold,i is the number of more digested prey $i$, both in the stomachs sampled at the particular time and location. An increase in the proportion of 'very fresh' or 'fresh' fish from one time of day to the next should correspond to ingestion of prey. The interpretation

285 of a decrease in the proportion is less clear, as this could be caused by digestion alone or by a combination of digestion and a low rate of ingestion. All predator length groups were considered together, as diel patterns in availability of the prey are likely to have a similar effect on all predators. The diel pattern in the intake of other prey in whiting stomachs has previously been shown not to vary between predator length 
290 groups (Rindorf, 2003). To make the diel pattern in the occurrence of 'very fresh' or 'fresh' fish prey directly comparable between locations, occurrence of 'very fresh' or 'fresh' prey $i$ at a location was calculated relative to the average occurrence of 'very fresh' or 'fresh' prey $i$ at the location:

$\frac{n_{\text {fresh }, i, k} /\left(n_{\text {fresh }, i, k}+n_{\text {old }, i, k}\right)}{\frac{1}{6} \sum_{k=1}^{k=6} n_{\text {fresh }, i, k} /\left(n_{\text {fresh }, i, k}+n_{\text {old }, i, k}\right)}$

295 where $k$ denotes time of day (4 hour sampling intervals) and 6 is the number of 4-hour intervals during 24 hours. Only locations where a minimum of five prey were recorded as 'very fresh' or 'fresh' were examined. This left sprat at location 1, herring at locations 1 and 3, whiting at location 3 and 5 and Norway pout and haddock at location 5. The length group 20 to $24.9 \mathrm{~cm}$ was only included for whiting prey as consumption of other fish by this group was low. A total of 633 fish prey were found in this subset of data and of these, 135 were classified as 'very fresh' or 'fresh'.

\section{Specialised predators}

A saturation level of the predator population which is below the digestive capacity could theoretically be due to full saturation of 'fish' specialists and no feeding on fish by the other individuals if some whiting specialise in eating fish (Chesson, 1984). Such prey specialisation should lead to a higher occurrence of 'old' fish relative to that of other prey in stomachs containing 'very fresh' or 'fresh' fish than is found in stomachs without 'very fresh' or 'fresh' fish. This was examined by

310 dividing the occurrence of 'old' fish with the occurrence of other prey to obtain the relative occurrence of fish, $R O$, in stomachs with and without 'very fresh' or 'fresh' fish: 


$$
R O=\frac{o_{f}+1}{o_{o t}+1}
$$

315 where of is the occurrence 'old' fish prey and oot is that of other 'old' prey. This relative occurrence was calculated for each predator length group at each location for both stomachs with and without 'very fresh' or 'fresh' fish in the cases where at least 5 stomachs in a length group at a given location contained both fish categorised as 'very fresh' or 'fresh' and more digested prey.

\section{Aggregative response and density dependent mortality}

The average catch of predators in each length group was estimated by first calculating the geometric average catch at each time of day and then the diel average as the mean of the catches at different times of day. Assuming the same catchability

325 for all three size groups of whiting, an index of the total mortality of sprat, herring and juvenile whiting, $M I_{i}$, was calculated as:

$$
M I_{i}=\frac{\sum_{l=1}^{l=3} T_{p d, l} n_{i, l}}{T_{i}}
$$

where $T_{p d, l}$ is the trawl catch of predators of length group $l, T_{i}$ denotes trawl catch of prey $i$ and $n_{i, l}$ is the number of prey $i$ eaten per day by a predator of length group $l . n_{i, l}$ was estimated as the weight of prey consumed divided by the mean weight of 'fresh' prey in the stomachs. This mortality index is proportional to the per cent mortality induced by whiting on the prey as

$$
\frac{\sum_{l=1}^{l=3} T_{p d, l} n_{i, l}}{T_{i}}=\frac{q_{p d}^{-1}}{q_{i}^{-1}} \frac{\sum_{l=1}^{l=3} N_{p d, l} n_{i, l}}{N_{i}}
$$


where $q_{p d}$ and $q_{i}$ is the catchability of the predator and prey species $i$, respectively. The relationship between this mortality index and predator and prey catch was investigated graphically.

\section{Results}

\section{Food intake}

The maximum daily intake in wet weight corresponded to 4.3 to $6.2 \%$ body weight (largest and smallest length group, respectively) at the warmest location and around $3.1 \%$ body weight at the coldest. The weight of the total food intake was highly correlated to temperature (correlations $=0.86$ to $0.95, \mathrm{P}>0=0.02$ to 0.04 , Fig. 3C and F). This effect was caused by an increase in consumption by weight of other

345 food with temperature (correlations $=0.84$ to $0.95, \mathrm{P}>0=0.01$ to 0.08 , Fig. $3 \mathrm{~B}$ ), whereby the predators maintained an intake of other food between 8 to $22 \%, 10$ to $20 \%$ and 8 to $17 \%$ of maximum daily ration for predators of length 20 to $24.9 \mathrm{~cm}, 25$ to $29.9 \mathrm{~cm}$ and 30 to $34.9 \mathrm{~cm}$, respectively (Fig. 3E). In contrast, the intake of fish was not significantly correlated to temperature neither when expressed by weight nor when expressed in percent of maximum intake (correlations $=-0.47$ to $0.80, \mathrm{P}>0=0.10$ to 0.67 , Fig. 3A and D). The fish intake in per cent of maximum varied between locations by a factor 36, 29 and 17 for the three length groups, respectively, whereas the intake of other food varied by no more than a factor 3 . There was no significant correlation between the intake of fish and other prey in either weight or percentage of 355 maximum ration (correlations $=-0.30$ to $0.73, \mathrm{P}>0=0.16$ to 0.81 ).

\section{Density of fish prey}


The maximum length of fish in the stomachs $\left(\mathrm{L}_{\mathrm{c}}\right)$ was $11 \mathrm{~cm}$ for gadoids and $14 \mathrm{~cm}$ for clupeids. Prey density varied greatly between locations (Fig. 4). Locations 1 and 3 were characterised by high sprat and herring density, respectively, whereas whiting catches were highest at locations 3 and 5. Haddock and Norway pout were caught in significant numbers at location 5 only. Location 4 was characterised by low catches of all prey species.

\section{Functional response}

The functional response to herring appeared to follow a type III response closely but the value of $\beta$ was quite low $(\beta \leq 1.8)$ and the response was only slightly different from a type II response (Fig. 5, Table 2). Sprat consumption was more erratic, but a fair fit was achieved by a type II response (Fig. 5, Table 2). As the low sprat consumption at location 3 was compensated for by high consumption of herring, total clupeid consumption showed a smooth response (Fig. 6, Table 2). Only minor improvements of the fit were obtained by fitting a type III rather than a type II response to total clupeid intake. However, whereas the type II response did not fall within the $95 \%$ confidence limits of all data points, the type III did. Whiting consumption increased

375 with density but no clear plateau was reached. Nevertheless, total gadoid consumption was well described by a type II response (Fig. 6, Table 2). The consumption of gadoids was characterised by a much higher half saturation constant ( $q \chi \geq 514)$ than the consumption of clupeids $(20 \leq q \chi \leq 159)$. The saturation level did not correspond to maximum intake rate for any of the species and the intake of the individual prey

380 groups in no case exceeded $20 \%$ of maximum daily ration (Fig. 5, 100\%*K in Table 3). 
The multispecies functional response provided very poor fits to the consumption of both larger predator groups (Fig. 7, Table 3). This was linked primarily to two events: A high gadoid intake at location 3, where herring density was 385 so high, that few other prey should have been consumed according to the model, and a high herring intake compared to that of sprat at location 1 , where the high density of the latter should have led to a higher intake of sprat than herring.

\section{Diel cycles in fish consumption}

All prey species but Norway pout showed two diel peaks in ingestion, one in the morning and one in the afternoon (Fig. 8). The location of the morning and afternoon peak corresponded closely to the period around dawn and sunset, respectively (Table 1). The ingestion around midday was low, though sprat appeared to be continually ingested from sometime around sunrise to later in the morning

395 hours. The intake of herring and haddock was slightly higher in the afternoon than in the morning whereas the opposite was true for sprat and whiting. However, the difference between the two peaks was minor, and as the number of observations was limited, it may be caused by random effects rather than actual differences between species. Norway pout showed only one peak around 15.00 hours, and thus differed

400 from the other prey species. Ingestion during darkness was low for all species but whiting at location 5. At this location, the afternoon peak in ingestion continued some hours after sunset.

\section{Specialised predators}

At the combinations of predator size and location where the minimum number of 5 stomachs containing both 'very fresh' or 'fresh' fish and old food were obtained, 
the relative 'old' fish occurrence was higher in stomachs containing 'very fresh' or 'fresh' fish than in stomachs without 'very fresh' or 'fresh' fish in 2 cases, whereas the opposite was true in the remaining 4 cases. 'Old' other prey were not completely

410 absent from stomachs containing 'very fresh' or 'fresh' fish in any case. No tendency for predators to specialize on fish could thus be detected.

\section{Aggregative response and density dependent mortality}

The natural $\log$ to the catch of prey was negatively correlated to that of the 415 predator for all combinations of prey and predator size group but two (Fig. 9). However, only the correlation between herring and whiting of length 25 to $29.9 \mathrm{~cm}$ (correlation $-0.92, \mathrm{P}=0.03$ ) was significant. As the probability of achieving one significant correlation in 9 by type II error is 0.30 , this result may be caused by chance effects. The mortality index of clupeids increased initially with density but

420 then declined again to very low values. Mortality of whiting decreased slightly with density, but the pattern was highly erratic. The mortality index was negatively correlated to prey density for all prey and predator combinations (Fig. 9), but none of these correlations were significant at the $5 \%$ level. There was thus some indication of negatively density dependent mortality of the prey caused by a combination of an

425 inverse numerical response and a saturation of individual predators, but the results were not conclusive.

\section{Discussion}

Consumption of clupeids by whiting was saturated around a total intake of 10 430 and $17 \%$ of maximum daily ration for predators of size 25 to $29.9 \mathrm{~cm}$ and 30 to 34.9 $\mathrm{cm}$, respectively, whereas gadoid consumption saturated around $6 \%$ of maximum 
daily ration for these two length groups. The predator population was thus never limited by gastric processing rate even though prey density was very high at some locations. The lack of saturation was not linked to high intake rates of other prey as the intake of these was uncorrelated with that of fish. Neither did it appear to be caused by the division of the population into 'fish'- and 'other food'-specialists as no indication was found in the stomach contents that individual predators foraged consistently on one prey type. As fish prey were predominantly eaten around dawn and dusk, the length of the twilight period may have eliminated the direct choice between fish and other prey, providing an explanation for the lack of negative correlation between the two. The total intake of fish prey was not enhanced by a consistent aggregative response and density dependent mortality occurred only at moderate densities of clupeids. No positive density dependence was found for juvenile whiting.

445 The discrepancy between the digestive capacity and saturation level may have several explanations though a number of them are unlikely to apply to the present study. First of all, the uncertainty about whether to include or exclude prey in pristine condition from the stomach content is a potential source of error in this study. If "very fresh' prey are included, the estimated consumption is on average increased by $0.04 \%$ 450 of the maximum daily ration compared to the estimate excluding 'very fresh' prey. The largest effect was found on the intake of gadoids in the largest predator group where intake was increased by $1 \%$ of maximum daily intake at location 3 . There was no effect on the estimated half saturation density and the effect on the intake of the remaining prey-predator combinations was negligible. However, the problem does stress the need to clarify the extent of trawl feeding. The estimation of the digestive saturation level of the predator is obviously highly dependent on the estimated 
maximum daily ration. Literature values of daily intake of whiting in the wild range from 1.42 to $3.82 \%$ (Malyshev, 1980; Patterson, 1985), and a daily intake of 3.4\% of body weight at a temperature of $14^{\circ} \mathrm{C}$ of whiting fed ad libitum in aquaria has been reported (Seyhan and Grove, 1998). The maximum daily intake rates used here correspond to $2.7 \%$ to $6.1 \%$ body weight, with an average of $3.3 \%$ and hence correspond well with reports from other studies.

Schooling fish are extremely patchy in their distribution, and patchiness of prey has been shown to decrease the slope of the initial increase of a type II response 465 (Essington et al., 2000). Though no evidence of a direct effect of patchiness on saturation level was found in the study of Essington et al. (2000), this may be an effect of the assumption of spatial overlap between predator and prey. If prey are patchily distributed over the trawled area and the predator does not show a local aggregative response, predators caught in one part of the trawl haul may not have overlapped spatially with the prey and may thus have been unable to feed on it. Such an effect would lead to an apparent saturation well below the physiological maximum as the predators which overlapped with the prey became saturated while predators in other areas fed on other prey. This effect would further explain the high intake of gadoids at the location where the predators were supposed to be saturated with 475 clupeids according to the multispecies functional response.

The estimation of the functional response relies on the assumption that the trawl catch is proportional to the density of the prey. A violation of this assumption will introduce variation around the relationship, but this variation only leads to bias if the proportionality factor increases with prey density (density dependent catchability). In 480 this case, the apparent saturation of the predators may be caused by an overestimation of prey density when trawl catches are large. There are indications that catchability of 
larger gadoids may increase with density (Godø et al., 1999). However, to produce the functional response recorded here, an average catch of 20 herring (the lowest catch at which saturation was reached) would have to correspond to the same ambient density as a catch of more than 9000 herring (the catch at the location with highest catches of herring, also corresponding to a saturated intake). Density dependent effects on catchability of this magnitude greatly exceed those reported by Godø et al. (1999). Further, the catchability of juvenile gadoids may actually decrease with density (Godø and Wespestad, 1993). However, even if the trawl reflects the density in the trawled volume accurately, this density is not necessarily equal to the density experienced by the predators. If the pelagic density of prey varies independently of that near the bottom, the predators may have experienced a different density than that reflected by the trawl. Though this may be a problem, it does not explain the lack of digestive saturation at high clupeid catch rates. To achieve this result, the predators should migrate vertically out of the high density area near the bottom to feed in layers of lower density. It was also assumed that all prey below the critical length were equally accessible to the predators. This assumption may not hold in all cases, but in the data at hand, the modal length of fish prey in the stomachs corresponded closely to the modal lengths observed in the trawl (12 to $14 \mathrm{~cm}$ for clupeids, 7 to $10 \mathrm{~cm}$ for 500 gadoids). Lastly, though the analyses obviously were hampered by the low number of locations sampled, this effect was partially alleviated by the high precision of the observed prey densities and consumption rates. This precision rendered the conclusions more credible than if they had been based on a large number of observations for which the variance of the estimates was unknown (Kendal and Stuart 505 1961). 
Lack of digestive saturation with one prey was also seen in a study of largemouth bass (Micropterus salmoides Lacepède), which consumed only $50 \%$ of maximum daily ration in their natural environment though prey density was very high (Essington et al., 2000). The lack of digestive saturation may thus be a generally 510 occurring phenomenon in piscivores. It is interesting to note the remarkable constancy of the intake of other food (Fig. 3). As the density of other food was not determined, it is not possible to link the intake to prey density and it remains unresolved whether the approximately constant intake was caused by saturation of the predator preying on a relatively unlimited resource at all locations or by a non-saturated predator feeding on 515 approximately equal prey densities at all locations.

The functional responses were generally well described by type II relationships though there was a slight tendency towards a type III shaped response. The type III response has previously been suggested to be linked to either learning by the predator or to a limited number of prey refuges (Murdoch, 1973). Though juvenile gadoids may utilise natural shelters on the bottom (Gotceitas et al., 1995), both herring and sprat are obligate schoolers and thus unlikely to have a limited number of refuges. These species rely on the protective value of the school and this increases with school size (Major, 1978; Parrish, 1992). Schooling should hence lead to a decrease in vulnerability of the individual prey with prey density and a type II rather than a type

525 III response. The intake of both clupeids and gadoids were well described by a common functional response for each prey group. However, the trawl catch of gadoids at which $50 \%$ of the saturation level was reached was much higher than for clupeids (Table 2). Due to the unknown catchabilities it is not possible to conclude whether this was caused by actual differences in density of gadoids and clupeids at 530 half-saturation. 
The diel pattern in intake was remarkably similar for all the five fish species as judged from the occurrence of 'very fresh' and 'fresh' prey. Peak feeding took place around dawn and dusk. It may therefore have been more relevant to compare the consumption directly to the density of prey at these times of day. However, the differences in feeding is probably related to increased vulnerability of the prey at moderate light levels (Hobson, 1986; Pitcher and Turner, 1986), and not necessarily to changes in density. Hence comparing dawn or dusk catches to consumption is unlikely to provide a more appropriate functional response. Unfortunately, data did not allow the duration of the non-feeding periods to be estimated, as it is not known

540 for how long a prey would be categories as 'very fresh' or 'fresh' after ingestion.

No evidence was found to support a division of the predators into 'fish' and 'other food' specialists, neither by this study, nor by Rindorf (2003) using a different method. However, the strength of the applied tests was probably inadequate to refute the hypothesis completely. If the predators tend to specialise on e.g. clupeids or 545 gadoids, this could potentially explain the poor fit of the multispecies functional response: though the predators could supposedly have been saturated with herring at location 3, they were observed to be feeding to a large extent on whiting. Thus the high availability of one prey did not affect the intake of the other. Such a pattern would naturally occur if the predatory whiting were divided into clupeid and gadoid 550 specialists.

Whether predator specialisation or lack of spatial overlap with the prey is the explanation of the lack of saturation at the population level, it does not alter the conclusions regarding the effect of the predator population on prey mortality. Clupeid intake by the largest predators followed a slightly sigmoid (type III) response and 555 these prey could potentially be regulated by whiting. However, as a consistent 
aggregative response was absent, mortality of clupeids peaked at intermediate densities (corresponding to $q \chi$ ) and then decreased to virtually zero at high densities. The clupeid prey thus rapidly escaped predator control and whiting predation was unlikely to have a direct regulatory effect at high densities. In comparison, the mortality of juvenile whiting was less variable with no clear trend. Note that the mortality index is proportional to prey catchability and therefore not readily comparable between species. However, as sprat and herring are likely to have approximately equal catchabilities (Sparholt, 1990) the mortality imposed on herring seems generally to exceed that imposed on sprat. This indicates either a higher

565 encounter rate with herring than sprat, a preference for herring over sprat or a combination of the two. As the mortality imposed by whiting on clupeids was virtually zero at high densities, it is clear that if whiting predation was the sole source of mortality, evolution should favour a strong aggregative response of clupeids. However, the beneficial effect of prey aggregation would be severely diminished if 570 the predator also concentrated in areas of high prey density (Anderson, 2001). Whether the negative correlation between herring and large whiting was achieved by the prey actively evading high predator densities or by other factors remains to be determined.

Though density dependence was not achieved directly from the combined 575 aggregative and functional responses, density dependence could arise if high prey density increased predator growth (Murdoch, 1973). Enhanced predator growth at high prey densities combined with increased attack rate and saturation level of larger predators could result in density dependent mortality after some time. While saturation level did not increase with predator size for gadoids (Table 2), both attack 580 rate and saturation level increased with predator size for clupeids, and for clupeids 
density dependent mortality can therefore potentially be introduced indirectly over a greater range of densities than indicated by the mortality index.

This study has demonstrated the error committed by assuming that the predator population is presented with a direct choice between numerous prey types, each of

585 which potentially could constitute the entire diet of the predator. Such assumptions are common in population models (Murdoch, 1973; Gislason and Helgason, 1985; Abrams, 1999; Post et al., 2000) and most models neglect predator specialisation and diel changes in prey availability. A predator experiencing a temporal segregation of the prey may maintain a high predation rate on a particular prey regardless of the 590 density of the alternative prey. Transient mutualism (Holt, 1977), where a prey species benefit from a high density of alternative prey, need not exist in such a system. Rather, the effect of alternative food on fish consumption may be the adverse as the predator population may be able to maintain a high density on the alternative food alone (apparent competition, Holt, 1977; Abrams and Matsuda, 1993). This

595 effect may lead to high predation rates even after several years of low fish prey density, keeping the prey at a low level. Such an effect may be present in some marine ecosystems, where low prey densities have been known to be sustained for a decade or more in locations that previously supported large densities (Collie and DeLong, 1999).

600

\section{Acknowledgements}

We thank P. Degnbol, who participated in the collection of the stomach data and A. D. Hansen who worked up the stomach contents so thoroughly. This research was supported by the SLIP research school under the Danish Network for Fisheries and Aquaculture Research (www.fishnet.dk) financed by the Danish Ministry for 
Food, Agriculture and Fisheries and the Danish Agricultural and Veterinary Research

Council. It was partly funded by a grant from the Danish Ministry of Food, Agriculture and Fisheries to the project 'Development of improved models of fisheries impact on marine fish stocks and ecosystems' (FIFOF-DFU-1).

610

\section{References}

Abrams, P., 1999. Is predator-mediated coexistence possible in unstable systems? Ecology 80 (2), 608-621.

Abrams, P. A., Ginzburg, L. R., 2000. The nature of predation: prey dependent, ratio 615 dependent or neither? Tree 15(8), 337-341.

Abrams, P., Matsuda, H., 1993. Effects of adaptive predatory and anti-predatory behaviour in a two-prey-one-predator system. Evol. Ecol. 7(3), 312-326.

Andersen, N. G., 1998. The effect of meal size on gastric evacuation in whiting. J. Fish Biol. 52(4), 743-755.

620 Andersen, N. G., 1999. The effects of predator size, temperature, and prey characteristics on gastric evacuation in whiting. J. Fish Biol. 54(2), 287-301.

Andersen, N. G., 2001. A gastric evacuation model for three predatory gadoids and implications of using pooled field data of stomach contents to estimate food rations. J. Fish Biol. 59(5), 1198-1217.

625 Andersen, N. G., Riis-Vestergaard, A. J., 2003. The effects of food consumption rate, body size and temperature on net food conversion efficiency in saithe and whiting. J. Fish Biol. 62(2), 395-412. 
Anderson, T. W., 2001. Predator responses, prey refuges and density-dependent mortality of a marine fish. Ecology 82(1), 245-257.

630 Arrhenius, F., Hansson, S., 1994. Functional response by young-of-the-year Baltic Sea herring (Clupea harengus). ICES C. M. 1994/J:16. Available from the International Council for the Exploration of the Sea, Palægade 2-4, $1261 \mathrm{~K}$, Copenhagen, Denmark.

*Bailey, R. S., 1975. Observations on the diel behaviour patterns of North Sea 635 gadoids in the pelagic phase. J. Mar. Biol. Assoc. U.K. 55, 133-142.

Bromley, P. J., Kell, L. T., 1995. Vertical migration patterns and spatial distribution of pelagic 0-group gadoids (cod, haddock, whiting and Norway pout) in the North Sea. ICES C. M. 1995/G:27. Available from the International Council for the Exploration of the Sea, Palægade 2-4, 1261 K, Copenhagen, Denmark.

640 Buckel, J. A., Stoner, A. W., 2000. Functional response and switching behavior of young-of-the-year piscivorous bluefish. J. Exp. Mar. Biol. Ecol. 245(1), 25-41.

Chesson, P. L., 1984. Variable predators and switching behavior. Theor. Popul. Biol. 26(1), 1-26.

Collie, J. S., DeLong, A. K., 1999. Multispecies interactions in the Georges Bank Fish 645 Community. In: Ecosystem approaches for fisheries management. University of Alaska Sea Grant, AK-SG-99-01, Fairbanks, pp. 187-210.

Colton, T. F., 1987. Extending functional response models to include a second prey type: an experimental test. Ecology 68(4), 900-912.

Davison, A. C., Hinkley, D. V., 1997. Bootstrap methods and their application. 650 Cambridge University Press, Cambridge. 
Essington, T. E., Hodgson, J. R., Kitchell, J. F., 2000. Role of satiation in the functional response of a piscivore, largemouth bass (Micropterus salmoides). Can. J. Fish. Aquat. Sci. 57(3), 548-556.

Gislason, H., Helgason, T., 1985. Species interaction in assessment of fish stocks with 655 special application to the North Sea. Dana 5, 1-44.

Godø, O. R., Wespestad, V. G., 1993. Monitoring changes in abundance of gadoids with varying availability to trawl and acoustic surveys. ICES J. Mar. Sci. 50(1), 3951.

Godø, O. R., Walsh, S. J., Engås, A., 1999. Investigating density-dependent 660 catchability in bottom-trawl surveys. ICES J. Mar. Sci. 56(3), 292-298.

Gordon, J. D. M., 1977. The fish populations in inshore waters of the west coast of Scotland. The food and feeding of the whiting (Merlangius merlangus L.). J. Fish Biol. 11(6), 513-529.

Gotceitas, V., Fraser, S., Brown, J. A., 1995. Habitat use by juvenile Atlantic cod 665 (Gadus morhua) in the presence of an actively foraging predator. Mar. Biol. 123(3), 421-430.

Grove, D. J., Crawford, C., 1980. Correlation between digestion rate and feeding frequency in the stomachless teleost, Blennius pholis L. J. Fish Biol. 16(3), 235-247.

Hilborn, R., Walters, C. J., 1992. Quantitative Fisheries Stock Assessment. Choice, 670 dynamics and uncertainty. Chapman and Hall Inc. New York.

Hobson, E. S., 1968. Predatory behavior of some shore fishes in the Gulf of California. US Fish. Wildl. Serv. Res. Rep. 73. Bureau of Sport Fisheries and Wildlife, Washington. 
Hobson, E. S., 1986. Predation on the pacific sand lance, Ammodytes hexapterus

675 (Pisces: Ammodytidae), during the transition between day and night in the southeastern Alaska. Copeia 1, 223-226.

Holling, C. S., 1959. The components of predation as revealed by a study of smallmammal predation of the European sawfly. Can. Entom. 96, 293-320.

Holt, R. D., 1977. Predation, apparent competition, and the structure of prey 680 communities. Theor. Popul. Biol. 12(2), 197-229.

Hossain, M. A. R., Haylor, G. S., Beveridge, M. C. M., 1998. Quantitative estimation of maximum daily feed intake of African catfish, Clarias gariepinus Burchell, fingerlings using radiography. Aquacult. Nutr. 4(3), 175-182.

ICES, 1997. Report of the multispecies assessment working group. ICES C. M. 685 1997/Assess:16. Available from the International Council for the Exploration of the Sea, Palægade 2-4, 1261 K, Copenhagen, Denmark.

Jeschke, J. M., Kopp, M., Tollrian, R., 2002. Predator functional responses: discriminating between handling and digesting prey. Ecol. Monogr. 72(1), 95-112.

Kendall, M. G., Stuart, A., 1961. The advanced Theory of Statistics, Volume 2: 690 Inference and relationship. Hafner, New York.

Koski, M. L., Johnson, B. M., 2002. Functional response of kokanee salmon (Oncorhynchus nerka) to Daphnia at different light levels. Can. J. Fish. Aquat. Sci. 59(4), 707-716.

Krylov, P. I., 1992. Density-dependent predation of Chaoborus flavicans on Daphnia 695 longispina in a small lake: the effect of prey size. Hydrobiologia 239(3), 131-140. 
Lipcius, R. N., Hines, A. H., 1986. Variable functional responses of a marine predator in dissimilar homogeneous microhabitats. Ecology 67(5), 1361-1371.

Main, J., Sangster, G. I., 1981. A study of the fish capture process in a bottom trawl by direct observations from an underwater vehicle. Scott. Fish. Res. Rep. 23, 1-24.

700 Major, P. F., 1977. Predator-prey interactions in schooling fishes during periods of twilight: a study of the silverside Pranesus insularum in Hawaii. Fish. Bull. 75(2), 415-426.

Major, P. F., 1978. Predator-prey interactions in two schooling fishes, Caranx ignobilis and Stolephorus purpureus. Anim. Behav. 26(Aug.), 760-777.

705 Malyshev, V. I., 1980. Evaluation of the food requirements of the North Sea whiting, Odontogadus merlangus. J. Ichtyol. 20(1), 68-74.

Mattila, J., Bonsdorff, E., 1998. Predation by juvenile flounder (Platichtys flesus L.): a test of prey vulnerability, predator preference, switching behaviour and functional response. J. Exp. Mar. Biol. Ecol. 227(2), 221-236.

710 Murdoch, W. W., 1973. The functional response of predators. J. Appl. Ecol. 10(1), $335-342$.

Murdoch, W. W., 1994. Population regulation in theory and practice. Ecology 75(2), 271-287.

Murdoch, W. W., Oaten, A., 1975. Predation and population stability. Adv. Ecol. Res. $7159,1-130$.

Parrish, J. K., 1992. Do predators 'shape' fish schools: interactions between predators and their schooling prey. Neth. J. Zool. 42(2-3), 358-370. 
Patterson, K. R., 1985. The trophic ecology of the whiting (Merlangius merlangus) in the Irish Sea and its significance to the Manx herring stock. J. Cons. Int. Explor. Mer 720 42(2), 152-161.

Pedersen, J., Hislop, J. R. G., 2001. Seasonal variations in the energy density of fishes in the North Sea. J. Fish Biol. 59(2), 380-389.

Pelletier, J. D., 2000. Are large complex ecosystems more unstable? A theoretical reassessment with predator switching. Math. Biosci. 163(1), 91-96.

725 Pennington, M., 1983. Efficient estimators of abundance for fish and plankton surveys. Biometrics 39(1), 281-286.

Pennington, M., 1985. Estimating the average food consumption by fish in the field from stomach contents data. Dana 5, 81-86.

Pitcher, T. J., Turner, J. R., 1986. Danger at dawn: experimental support for the

730 twilight hypothesis in shoaling minnows. J. Fish Biol. 29(suppl. A), 59-70.

Post, D. M., Conners, M. E., Goldberg, D. S., 2000. Prey preference by a top predator and the stability of linked food chains. Ecology 81(1), 8-14.

Real, L. A., 1979. Ecological determinants of functional response. Ecology 60(3), $481-485$.

735 Rindorf, A., 2002. The effect of stomach fullness on food intake of whiting in the North Sea. J. Fish Biol. 61(3), 579-593.

Rindorf, A., 2003. Diel feeding pattern of whiting in the North Sea. Mar. Ecol. Prog. Ser. 249, 265-276.

Rindorf, A., 2004. Estimation of in situ evacuation rates. J. Fish Biol. 65, 262-281.

740 Rindorf, A., Lewy, P., in prep. Estimation of food intake. Submitted to Can. J. Fish. Aquat. Sci. 
Seyhan, K., Grove, D. J., 1998. Food consumption of whiting, Merlangius merlangus, in the Eastern Irish Sea. Fish. Res. 38(3), 233-245.

Seyhan, K., Grove, D. J., King, J., 1998. Feeding behaviour of whiting, Merlangius merlangus, L. in captivity. Fish. Res. 34(1), 39-45.

Sims, D. W., Davies, S. J., Bone, Q., 1996. Gastric emptying rate and return of appetite in lesser spotted dogfish, Scyliorhinus canicula (Chondrichthyes: Elasmobranchii). J. Mar. Biol. Assoc. U.K. 76(2), 479-491.

Sparholt, H., 1990. An estimate of the total biomass of fish in the North Sea. J. Cons Int. Eplor. Mer 46(2), 200-210.

Townsend, C. R., Risebrow, A. J., 1982. The influence of light level on the functional response of a zooplanktonivorous fish. Oecologia 53(3), 293-295.

Wennhage, H., 2002. Vulnerability of newly settled plaice (Pleuronectes platessa L.) to predation: effects of habitat structure and predator functional response. J. Exp. Mar. Biol. Ecol. 269(2), 129-145.

\section{Appendix}

\section{Estimation of food intake} location was calculated over a 48 hour period as

$$
W_{i}=\frac{\rho_{i}^{\prime}}{13} \sum_{j=1}^{13} \sqrt{S_{i, j}}+\frac{1}{48}\left(\hat{S_{i, 13}}-\hat{S_{i, 1}}\right)
$$


The estimation of average hourly intake of species $i$ by eq. 1 requires an estimate of prey species specific evacuation rate, $\rho_{i}^{\prime}$. This evacuation rate was corrected for the effect of other food in the stomach on the evacuation of prey $i$ by estimating $\rho_{i}^{\prime}$ as

$\rho_{i}^{\prime}=\sqrt{\pi_{i}}\left(\pi_{i} \rho_{i}+\left(1-\pi_{i}\right) \rho_{\text {res }}\right)$

where $\pi_{i}$ is the proportion of the contents which consists of species $i$ in the stomachs where $i$ is found, $\rho_{i}$ is the evacuation rate of species $i$, and $\rho_{\text {res }}$ is the evacuation rate of the remaining stomach contents (Rindorf and Lewy, in press.). Evacuation rates for the five prey species are given in Table 1A. The estimated evacuation rates of the remaining contents are given in Rindorf and Lewy (in press.) for the size group 25 to $29.9 \mathrm{~cm}$ and the estimates for the adjacent groups were calculated by the same method 775 as the estimates for 25 to $29.9 \mathrm{~cm}$ whiting. Food intake was estimated separately for each predator length group and the estimation of $\hat{S_{i, j}}$ and $\hat{\sqrt{S_{i, j}}}$ followed the description given in Rindorf and Lewy (in press.). Briefly, the average content of prey $i$ at a given time and location was estimated as the product of the proportion of stomachs that contained prey $i$ and the mean weight of prey $i$ present in the stomachs where prey $i$ occurred. Both occurrence and mean weight of each prey species were estimated by using generalised linear models to evaluate the effect of time of day, predator length and location and to reveal if trends over the sampling period were present (Rindorf, 2003; 2004). Insignificant effects were removed from the models and the reduced models used to estimate occurrence and mean weight. Thus, if the 785 occurrence of a prey did not differ between samples, a common occurrence was estimated for all samples taken from the given predator length group and location. The procedure is described in detail elsewhere (Rindorf, 2003; 2004; Rindorf and 
Lewy, in press.). It provides more precise estimates than a simple sample average but complicates the calculation of confidence limits of the estimated consumption. These were therefore estimated by parametric bootstrap as described in the appendix.

\section{Estimation of variance of estimated trawl catch and food intake}

The variance of the estimated consumption was calculated by parametric bootstrap (Davison and Hinkley, 1997). This was performed by simulating a new data set containing the same number of hauls and stomachs collected within each haul as the original data set. Each simulated stomach had a probability of containing the particular prey equal to the occurrence of this prey (Rindorf, 2003). If the prey was present in the simulated stomach, the mean weight was simulated from a gamma distribution with the shape and scale parameters estimated from the original data

800 (Rindorf, 2004). A set of stomach contents were simulated for each prey at each location. The simulated stomachs were then used to estimate consumption by the exact same procedure as was used analysing the original data, i.e. by first fitting generalised linear models to the food composition as described by Rindorf (2003; 2004) and then estimating consumption by (2). This estimation of consumption from simulated data was performed 500 times and the results were used to calculate the variance of the estimated consumption.

The variance of the average trawl catch was estimated in a similar way. A new data set was simulated containing the same number of hauls as the original data set. Each haul had a probability of containing the particular prey equal to the proportion of

810 hauls in which the prey was found in the original data from the location. If a simulated haul contained the prey, the total number caught was simulated from a gamma distribution with the scale parameter equal to the estimated parameter at the given 
location and time. The shape parameter (and hence the coefficient of variation) was set to the common shape of all hauls in the observed data. The proportion of the catch

815 which consisted of possible prey was simulated from the observed number of fish measured and the proportion of these which were below $\mathrm{L}_{\mathrm{c}}$ at the given location and time of day. From this simulated series of hauls, an estimated trawl catch was calculated for each location and prey by (3). The procedure was performed 500 times for each prey and the variance of the estimated catch calculated as the variance of the estimated trawl catches in the simulated data.

\section{Estimation of maximum daily ration of whiting}

The maximum daily intake of whiting has been estimated by recording the voluntary intake of sandeel by fish in aquaria (Andersen and Riis-Vestergaard, 2003).

825 However, as other experiments indicate that the factor limiting food intake is stomach fullness (Grove and Crawford, 1980; Sims et al., 1996; Hossain et al., 1998; Seyhan et al., 1998) and as stomach fullness depends on both intake rate and stomach evacuation rate, evacuation rate and maximum food intake are intrinsically linked. The results from the study of Andersen and Riis-Vestergaard (2003) can hence not be used

830 directly in the present study, as the whiting in the present study had a varied diet consisting of both rapidly and slowly evacuated prey. Instead, the maximum maintained amount of food in the stomach, $S_{\max }$, can be estimated and used to estimate maximum daily ration.

The maximum food intake in gram sandeel, $W_{\text {max,sandeel }}$ of whiting can be 835 described by the relationship

$$
W_{\max , \text { sandeel }}=0.00122 L^{2.28} e^{0.076 t e m p}
$$


where $L$ is total length of the predator and temp is temperature in ${ }^{\circ} \mathrm{C}$ (Andersen and Riis-Vestergaard, 2003). As

$W_{\text {max }, \text { sandeel }}=24 \rho_{\text {sandeel }} \sqrt{S_{\max }}$

840 where

$\rho_{\text {sandeel }}=0.000271 L^{1.44} e^{0.078 \text { temp }}$

A3

is the temperature and predator size dependent evacuation rate of sandeel with an energy density of $6.08 \mathrm{KJ} / \mathrm{g}$ (Pennington, 1985; Andersen, 2001), this corresponds to a sustained stomach content of

$845 \quad S_{\max }=\left(\frac{W_{\max }}{24 \rho_{\text {sandeel }}}\right)^{2}$

Inserting A1 and A3 in A2, the maximum sustainable stomach content becomes

$S_{\max }=0.0352 L^{1.68} e^{-0.004 t e m p}$

The maximum daily food intake can then be calculated directly from $S_{\max }$ as

$W_{\max }=24 \rho_{\text {tot }} \sqrt{S_{\max }}$

850 where $\rho_{t o t}$ is the temperature and predator size dependent evacuation rate of the total stomach content (Pennington, 1985). Ptot was calculated by using the relationship between evacuation rate, predator length and temperature given by Andersen (1998) and is described in detail in Rindorf and Lewy (in press). The estimation resulted in an estimate of the maximum wet weight consumed by each predator size group at 855 each location. 
Table 1. Depth, bottom temperature, sunrise and sunset and civil twilight (dawn/dusk) at the five locations

\begin{tabular}{lccccc}
\hline Location & 1 & 2 & 3 & 4 & 5 \\
\hline Bottom depth $(\mathrm{m})$ & 44 & 46 & 53 & 73 & 137 \\
Bottom temperature $\left({ }^{\circ} \mathrm{C}\right)$ & 16.7 & 13.7 & 10.6 & 8.2 & 8.6 \\
Sunrise & 4.55 & 4.44 & 4.42 & 5.01 & 5.1 \\
Sunset & 18.17 & 18.27 & 18.32 & 18.33 & 18.37 \\
Civil twilight (dawn) & 4.18 & 4.06 & 4.03 & 4.23 & 4.32 \\
Civil twilight (dusk) & 18.54 & 19.05 & 19.12 & 19.11 & 19.17 \\
\hline
\end{tabular}

860 
Table 2. Parameter estimates of functional response curves. Parameters are given when a plateau in consumption was reached. $\mathrm{r}^{2}$ was calculated in the cases where the prey was consumed at 4 or more locations.

\begin{tabular}{|c|c|c|c|c|c|c|}
\hline Prey & $\begin{array}{c}\text { Predator } \\
\text { length }\end{array}$ & Type & $K$ & $9 \chi$ & $\beta$ & $\mathrm{r}^{2}$ \\
\hline \multirow[t]{3}{*}{ Sprat } & $20-24.9$ & II & 0.0032 & 46 & 1 & - \\
\hline & $25-29.9$ & II & 0.019 & 9.5 & 1 & $0.76^{\mathrm{b}}$ \\
\hline & $30-34.9$ & II & 0.020 & 11 & 1 & $0.59^{b}$ \\
\hline \multirow[t]{5}{*}{ Herring } & $20-24.9$ & II & 0.013 & 17 & 1 & - \\
\hline & $25-29.9$ & II & 0.085 & 36 & 1 & 0.87 \\
\hline & $25-29.9$ & III & 0.082 & 15 & 1.5 & 0.92 \\
\hline & $30-34.9$ & II & 0.17 & 57 & 1 & 0.88 \\
\hline & $30-34.9$ & III & 0.16 & 14 & 1.8 & 0.98 \\
\hline \multirow[t]{5}{*}{ Whiting } & $20-24.9$ & II & - & - & 1 & 0.70 \\
\hline & $20-24.9$ & III & - & - & 1.7 & 0.70 \\
\hline & $25-29.9$ & II & - & - & 1 & 0.65 \\
\hline & $25-29.9$ & III & 0.089 & 1586 & 1.3 & 0.66 \\
\hline & $30-34.9$ & $\mathrm{II}^{\mathrm{a}}$ & 0.022 & 243 & 1 & 0.37 \\
\hline \multirow[t]{5}{*}{ Clupeids } & $20-24.9$ & II & 0.014 & 159 & 1 & - \\
\hline & $25-29.9$ & II & 0.10 & 59 & 1 & 0.95 \\
\hline & $25-29.9$ & III & 0.095 & 24 & 1.4 & 0.97 \\
\hline & $30-34.9$ & II & 0.17 & 95 & 1 & 0.93 \\
\hline & $30-34.9$ & III & 0.16 & 20 & 1.8 & 0.99 \\
\hline \multirow[t]{5}{*}{ Gadoids } & $20-24.9$ & II & - & - & 1 & 0.85 \\
\hline & $20-24.9$ & III & - & - & 1.5 & 0.85 \\
\hline & $25-29.9$ & II & 0.12 & 2907 & 1 & 0.90 \\
\hline & $25-29.9$ & III & 0.055 & 514 & 1.7 & 0.93 \\
\hline & $30-34.9$ & $\mathrm{II}^{\mathrm{a}}$ & 0.063 & 965 & 1 & 0.79 \\
\hline
\end{tabular}

a Type III was identical to type II

${ }^{\mathrm{b}}$ Only 4 locations included 
870 Table 3. Summary of the multispecies functional response for the two larger predator groups.

\begin{tabular}{lcccccc}
\hline & Predator & & & & & \\
Prey & length & $a_{i}$ & $a_{i} t_{i}$ & $K_{i}$ & $q_{i} \chi_{i}$ & $\mathrm{r}^{2}$ \\
\hline Sprat & & 0.386 & 0.83 & 0.47 & 1.21 & \\
Herring & $25-29.9$ & 0.585 & 0.57 & 1.03 & 1.75 & 0.27 \\
Gadoids & & 0.029 & 1.63 & 0.018 & 0.61 & \\
& & & & & & \\
Sprat & & 0.315 & 0.71 & 0.32 & 1.42 & \\
Herring & $30-34.9$ & 0.656 & 0.59 & 1.12 & 1.70 & 0.45 \\
Gadoids & & 0.029 & 1.19 & 0.025 & 0.84 & \\
\hline
\end{tabular}


Table 1A. Estimation of evacuation rates. The evacuation rate of prey $i$ in predators of 875 size $L$ caught at a location with temperature temp was estimated as $\rho_{i}=$ $\rho_{L T, i} L^{1.44} \mathrm{e}^{0.078 t e m p}$ (Andersen, 1999). $\rho_{\mathrm{LT}, i}$ was calculated from the relationship $\rho_{L T, i}=0.00128 E_{i}^{-0.86}$ (Andersen, 2001), where $E_{i}$ is energy density of the prey in $\mathrm{kJ} / \mathrm{g}$ taken from Pedersen and Hislop (2001).

\begin{tabular}{lcc}
\hline Prey group & $E_{i}$ & $10^{3} \rho_{\mathrm{LT}, \mathrm{i}}$ \\
\hline Haddock & 3.9 & 0.397 \\
Herring & 4.3 & 0.368 \\
Norway pout & 4.7 & 0.338 \\
Sprat & 6.5 & 0.256 \\
Whiting & 3.7 & 0.415 \\
\hline
\end{tabular}


Fig. 1. Map of sampling locations.

Fig. 2. Theoretical type II (--) and III (-) responses. A: Arithmetic scale. B: 885 Logarithmic scale. Parameter values: type II: $q \chi=20, \beta=1, \mathrm{~K}=100$, type III: $q \chi=20$, $\beta=3, \mathrm{~K}=100$. Notice how clear the difference between the lower part of the curves is on B compared to A.

Fig. 3. The amount of fish (clupeids and gadoids) (A and D), other food (B and E) and fish and other food together ( $\mathrm{C}$ and $\mathrm{F}$ ) consumed per predator per day as a function of temperature. A, B and C: consumption in $\mathrm{g}$. D, E and F: consumption in per cent of maximum daily ration. Predator size 20 to $24.9 \mathrm{~cm}(\boldsymbol{\Delta}), 25$ to $29.9 \mathrm{~cm}(\boldsymbol{\bullet})$ and 30 to $34.9 \mathrm{~cm}(\boldsymbol{\square})$.

895 Fig. 4. Average number of fish smaller than $\mathrm{L}_{c}$ caught per trawl hour of each species. Sprat $(\square)$, herring $(\square)$, whiting ( $\square$ ), haddock ( $\square$ ) and Norway pout $(\Xi)$. Bars indicate $95 \%$ confidence limits of the mean.

Fig. 5. Amount of prey consumed per predator per day divided by maximum daily ration as a function of number of prey caught per trawl hour. A, B and C: Sprat, D, E and F: Herring. G, H and I: Whiting. Predator size 20 to $24.9 \mathrm{~cm}$ (left panel), 25 to $29.9 \mathrm{~cm}$ (middle panel) and 30 to $34.9 \mathrm{~cm}$ (right panel). Bars indicate 95\% confidence limits of the estimate. ---: Fitted type II response. - - Fitted type III response.

905 Fig. 6. Amount of each prey group consumed relative to maximum daily ration as a function of number of prey caught per trawl hour. A, B and C: Clupeids (sprat and 
herring), D, E and F: Gadoids (whiting, haddock and Norway pout). G, H and I: All fish prey. Predator size 20 to $24.9 \mathrm{~cm}$ (left panel), 25 to $29.9 \mathrm{~cm}$ (middle panel) and 30 to $34.9 \mathrm{~cm}$ (right panel). Bars indicate $95 \%$ confidence limits of the estimate. - - :

910 Fitted type II response. — : Fitted type III response.

Fig. 7. Fit of the multispecies functional response to consumption. Intake of sprat (A and D), herring (B and E) and whiting (C and F). Observed: $\square$. Bars indicate 95\% confidence intervals of the intake. Predicted by multispecies model: $\mathbf{\square}$. Predator length 25 to $29.9 \mathrm{~cm}$ (A, B and C) and 30 to $34.9 \mathrm{~cm}$ (D, E and F).

915

Fig. 8. The proportion of prey found in the stomachs classified as 'fresh' relative to the average proportion for the given prey and location as a function of time of day. A: Sprat. B: Herring. C: Whiting. D: Haddock. E: Norway pout. Location $1(\boldsymbol{\Delta}), 3(\diamond)$ and $5(\mathbb{\square})$. Open symbols indicate times where less than 5 prey were present for 920 classification. Shaded areas indicate period of darkness.

Fig. 9. Number of predatory whiting caught and mortality index induced by these whiting on each prey as a function of number of prey caught. A and D: Sprat. B and E: Herring. C and F: Whiting. Predator size 20 to $24.9 \mathrm{~cm}(\boldsymbol{\Delta}), 25$ to $29.9 \mathrm{~cm}(\diamond), 30$ 925 to $34.9 \mathrm{~cm}(\boldsymbol{\square})$ and all predator length together $(*)$. Symbols placed directly on the horizontal axis indicate zero mortality. 


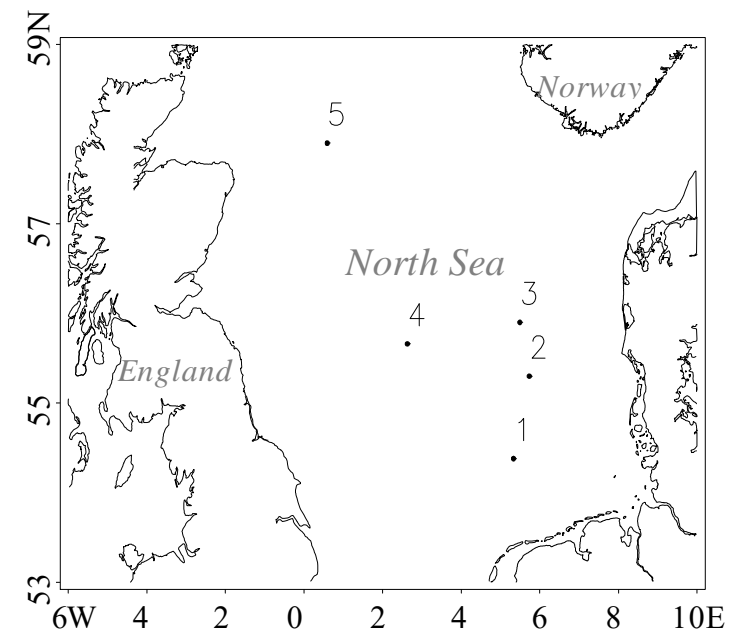

930

Fig. 1 

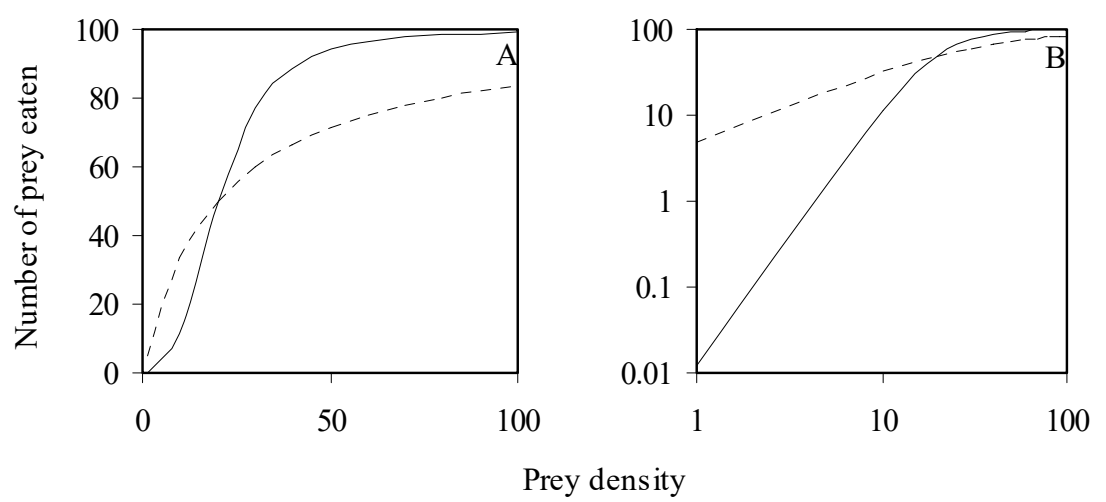

935

Fig. 2 

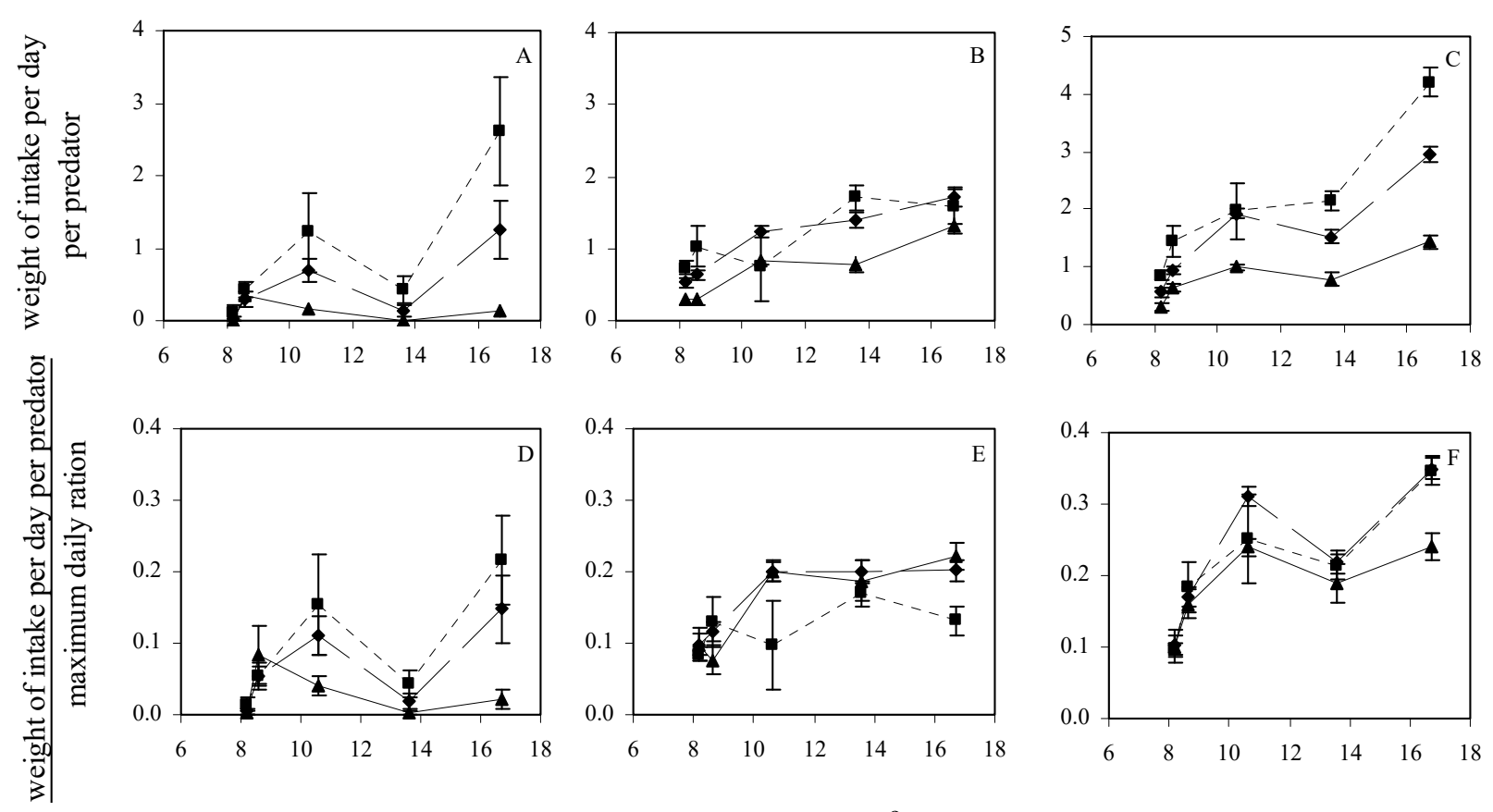

Temperature $\left({ }^{\circ} \mathrm{C}\right)$

940

Fig. 3 


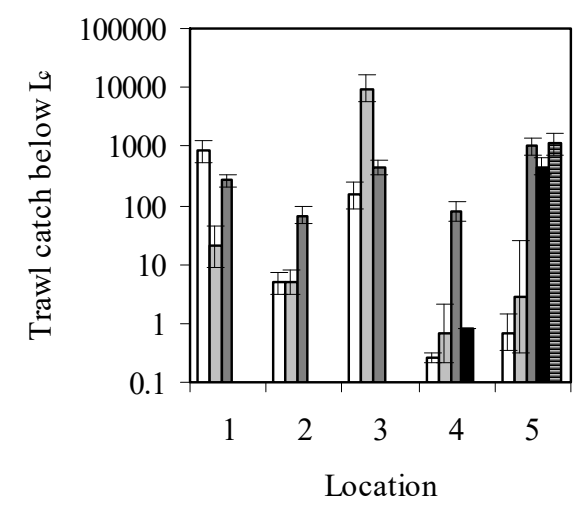

945

Fig. 4 

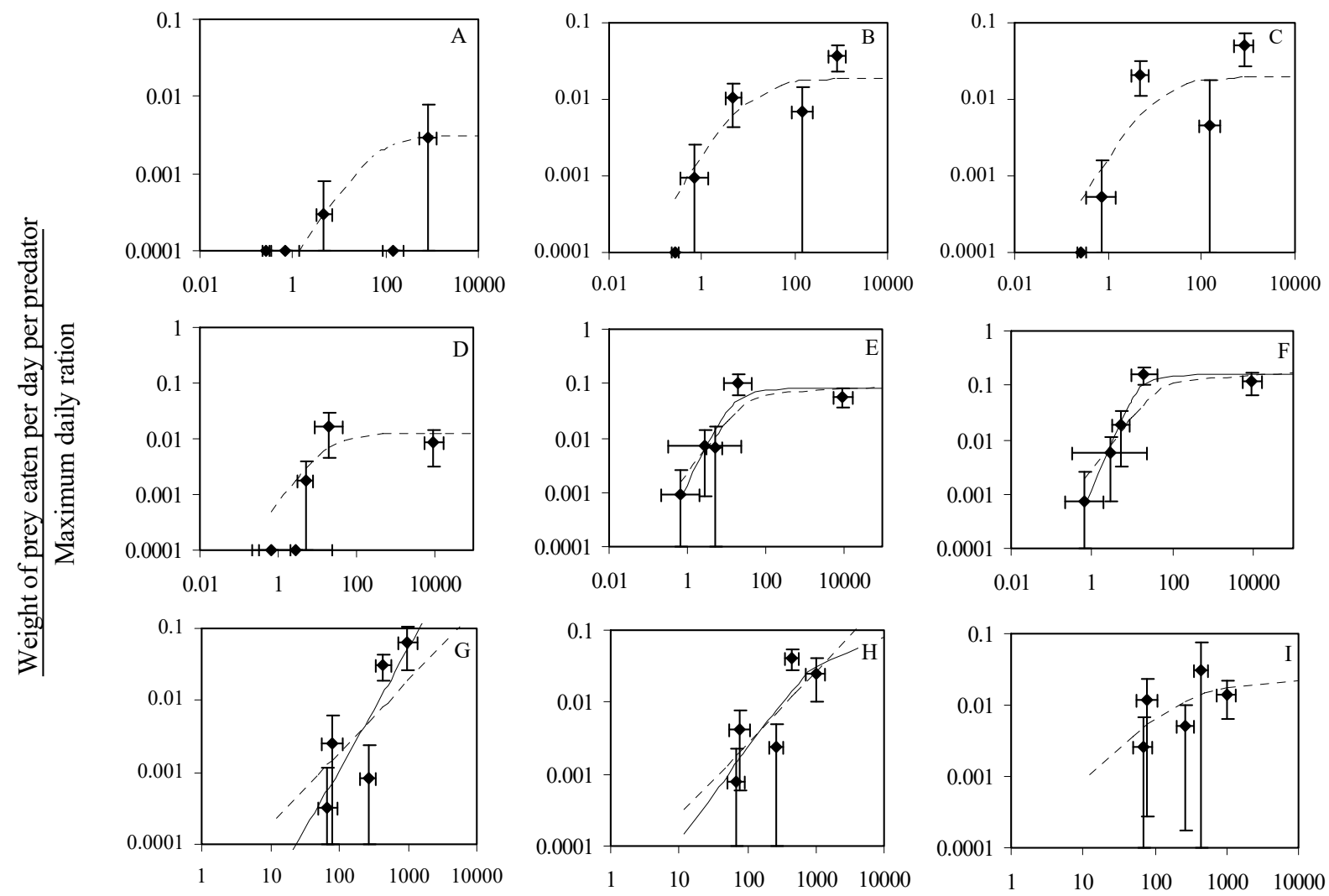

950

Fig. 5 


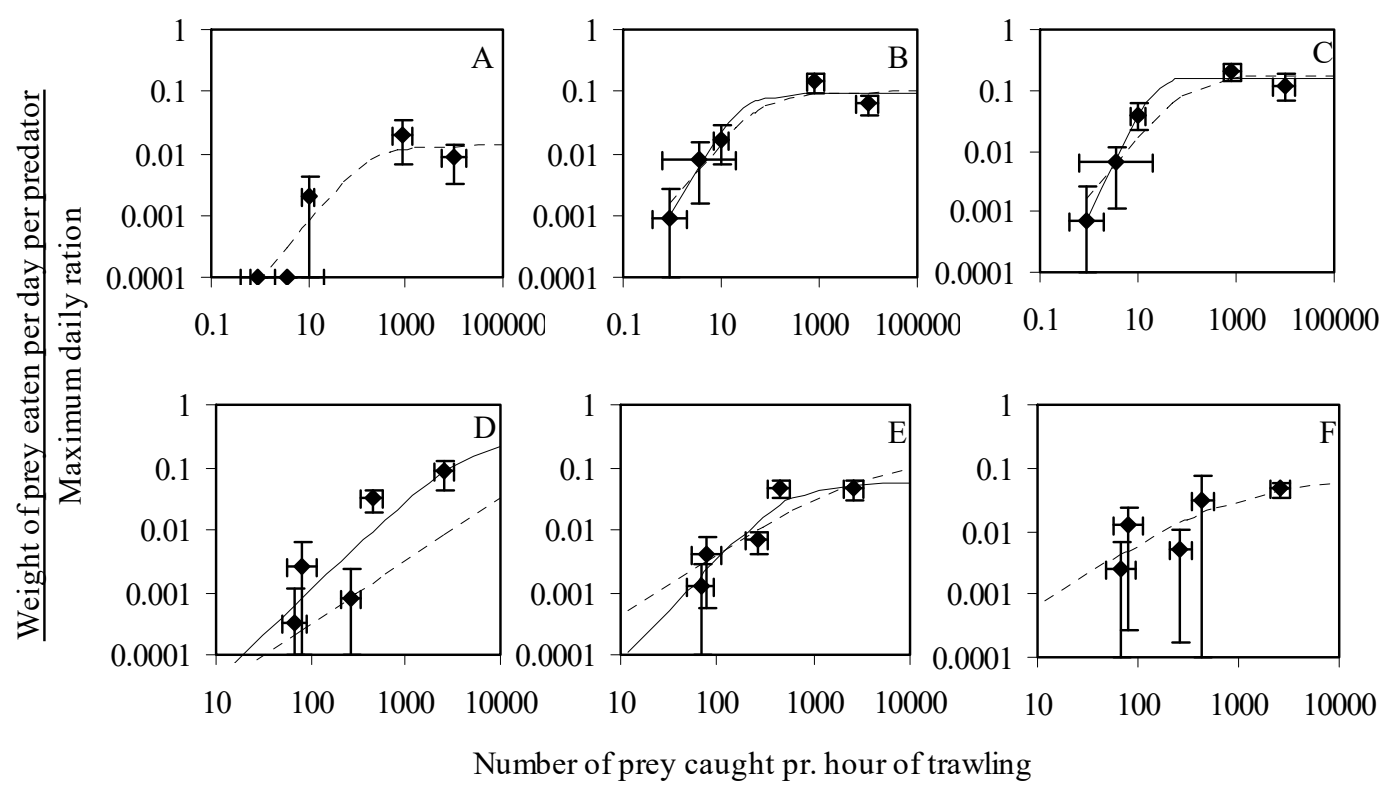

955

Fig. 6 


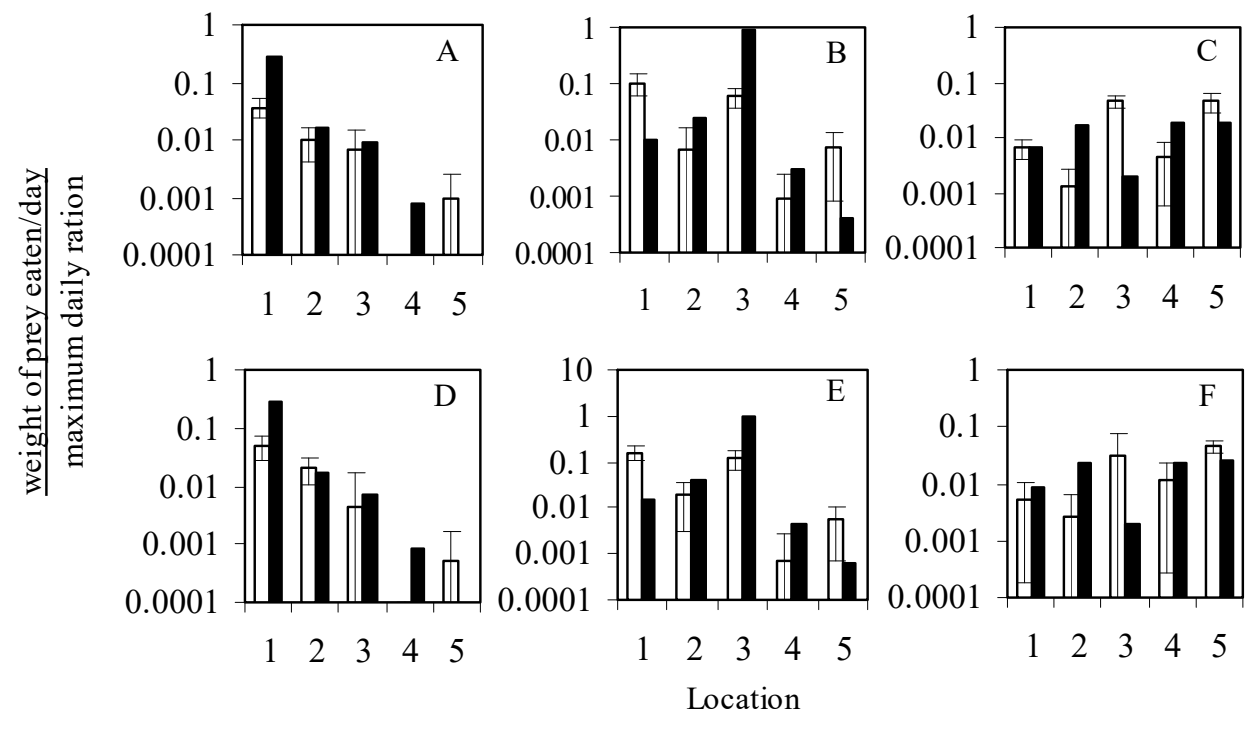

Fig. 7 

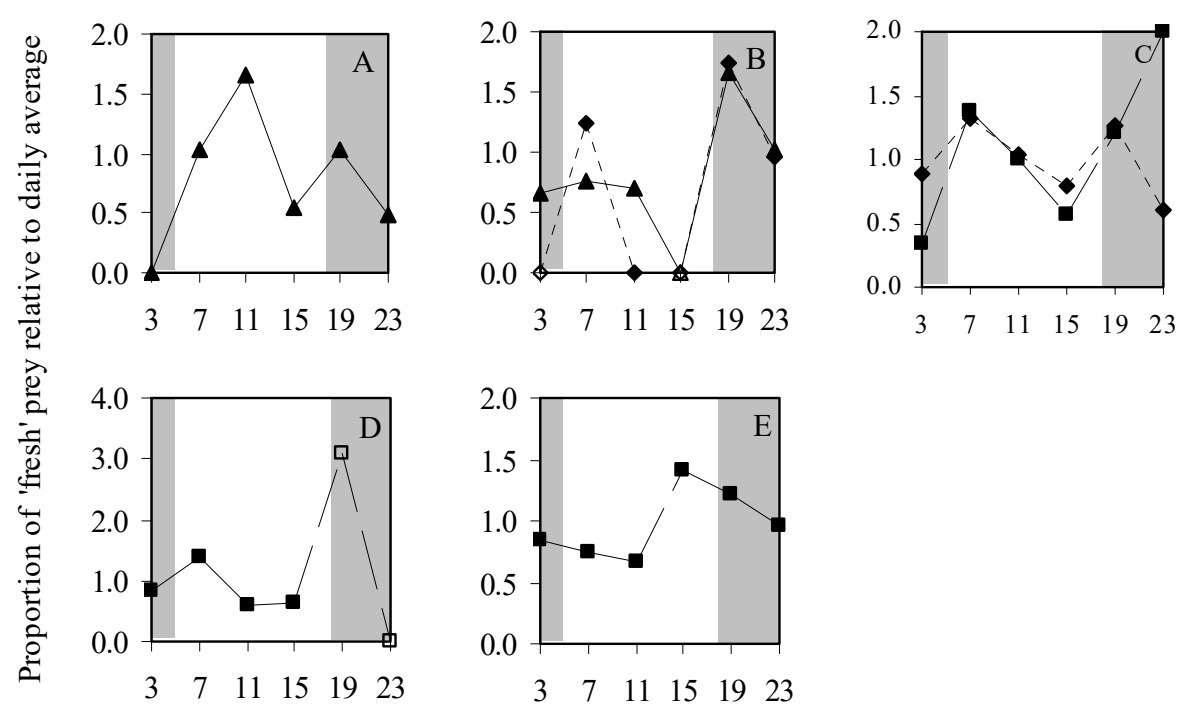

Time of day

$965 \quad$ Fig. 8 

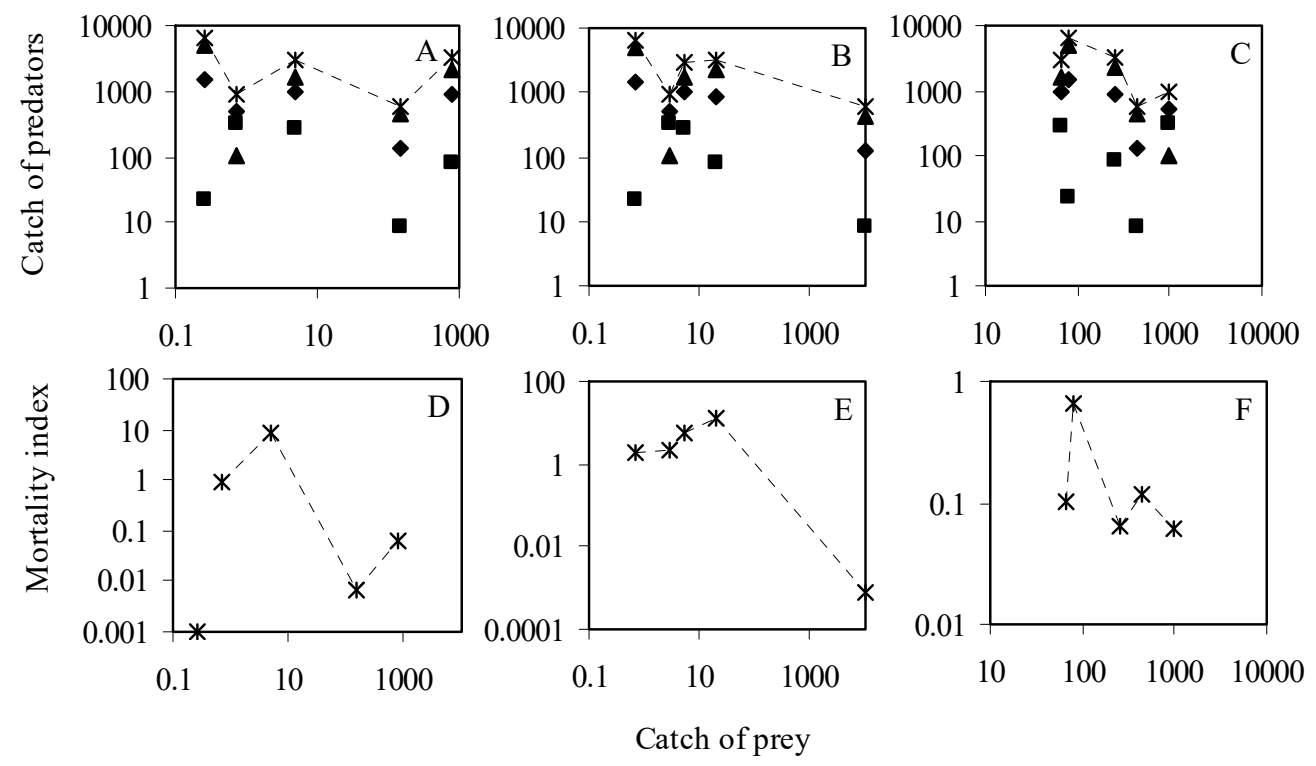

Fig. 9 